\title{
The Influence of Stress on Erythrocyte Sedimentary Rate (ESR) for the Staff of College of Science - Diyala University
}

\author{
Mohammed A. Farhan*, Wafaa Sh. Al-Zuhairi and Nuha Abduljaleel Imran \\ Department of Chemistry, College of Science, Diyala University, Diyala, Iraq \\ e-mail: alshamary_198840@yahoo.com \\ * Corresponding author
}

\begin{abstract}
This study was applied on 15 teaching staffs (10 men and 5 women) from Department of Chemistry, Diyala University to measure the effect of the stress during the working hours on the erythrocyte sedimentation rate (ESR). Blood samples were taken from the teaching staffs before and after the work, as well as another sample after the end of the working hours. The results were analyzed using a statistical program. Most of the results were within the normal level of ESR. There is no stress effect on teaching staffs during the working hours.
\end{abstract}

\section{Introduction}

The erythrocyte sedimentation rate (ESR) test, first described about 70 years ago, is one of the most widely performed laboratory tests. The Westergren method to measure the ESR has remained essentially unchanged since its inception and was recommended as the method of choice by the International Council for Standardization in Haematology in 1973 and 1977. Although over the years other methods to measure the ESR have been introduced for routine use, e.g., the Zeta Sedimentation Ratio Determination (ZSR), the Westergren method remains the benchmark against which other methods can be, and are, evaluated $[1,2]$.

Received: January 28, 2019; Revised: February 8, 2019; Accepted: February 11, 2019

Keywords and phrases: ESR, RBC, stress, zeta potential, proteins.

Copyright (C) 2019 Mohammed A. Farhan et al. This is an open access article distributed under the Creative Commons Attribution License, which permits unrestricted use, distribution, and reproduction in any medium, provided the original work is properly cited. 
The sedimentation of red cells in autologous plasma provides a measure of the acutephase reaction to inflammation. The term "erythrocyte sedimentation rate" is the traditional term, although a single measurement of the amount of fall of the red cells after 60 minutes is not truly a rate. Red cell sedimentation is accelerated by an increase in the plasma concentration of so-called "acute-phase proteins," which are increased in acute tissue damage, chronic inflammation, chronic infection, and pregnancy [3].

It is a known fact that our bodies are exposed continually to bacteria, viruses, fungi, and parasites, all of which occur normally and to varying degrees in the skin, the mouth, the respiratory passageways, the intestinal tract, the lining membranes of the eyes, and even the urinary tract. Many of these infectious agents are capable of causing serious abnormal physiologic function or even death if they invade the deeper tissues. In addition, these are exposed intermittently to other highly infectious bacteria and viruses besides those that are normally present and those can cause acute lethal diseases such as pneumonia, streptococcal infection, and typhoid fever.

While, ESR is a measurement of how quickly red blood cells fall to the bottom of a test tube. When swelling and inflammation are present, the blood's proteins clump together and become heavier than normal. Thus, when measured, they fall and settle faster at the bottom of the test tube. The erythrocyte sedimentation rate (ESR) determination is a simple and inexpensive laboratory test that is frequently ordered in clinical medicine. The test measures the distance that erythrocytes have fallen after one hour in a vertical column of anticoagulated blood under the influence of gravity. The basic factors influencing the ESR have been understood since the early part of this century, the amount of fibrinogen in the blood directly correlates with the ESR. Generally, the faster the blood calls fall, the more severe the inflammation. The distance red blood cells travel in one hour in a sample of blood as they settle to the bottom of a test tube. The sedimentations rate is increased in inflammation, infection, cancer, rheumatic diseases, and diseases of the blood and bone marrow. It is also called sedimentation rate [4]. The ESR reflects both the increase in certain accelerating proteins, such as fibrinogen and gamma globulins, and the decrease in retarding proteins, such as albumin. This is an advantage for the monitoring of rheumatoid arthritis but decreases the sensitivity and specificity of the test when used for disease screening purposes [5]. There is a relationship between stress of work and proteins that lead to increase ESR, methods related to cell agglutination caused by antigen-antibody interactions when there are many stress. There are also blood antigens on the RBC 
membrane, such as A antigen and D antigen [6]. Sedimentation is also accelerated in anemia, which may or may not accompany these diseases or conditions. In addition, the ESR is somewhat sensitive to the shape of red cells. For example, red cells such as those seen in thalassemia are broader and thinner than normal and sediment less rapidly than normal erythrocytes. This document describes a reference procedure for the erythrocyte sedimentation rate (ESR) test, as well as a selected procedure. This selected method is based on the original methodology of Fåhræus and Westergren, which used diluted blood in open-ended, Westergren-type glass pipettes of 300-mm length mounted vertically in a rack or stand [1]. Red blood cell (RBC) aggregation in the blood stream is prevented by the zeta potential created by its negatively charged membrane as shown in Figure 1.

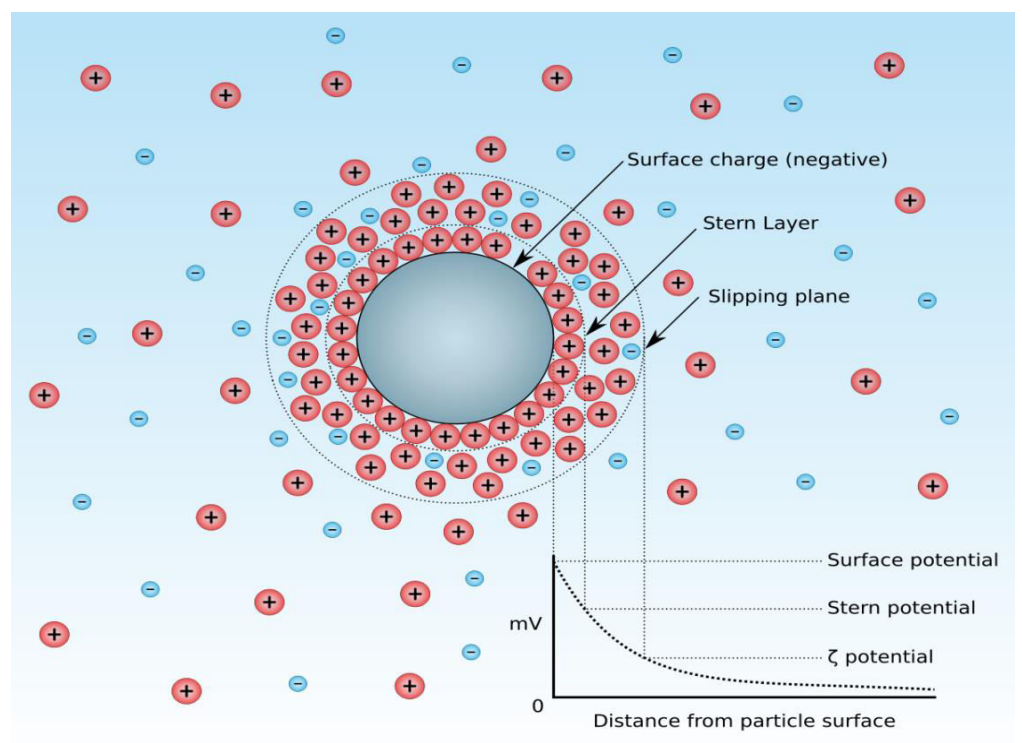

Figure 1. Zeta forces.

RBC membrane proteins are responsible for this agglutination that can be specific or nonspecific. When the agglutination is nonspecific, some of the membrane proteins from one cell link to some membrane proteins of the other cell. RBCs agglutinated in a nonspecific way are called RBCs rouleaux as shown in Figure 2. When the agglutination is specific, it is caused by antigen-antibody interaction.

The identification of the antibodies against the erythrocyte antigens is of fundamental importance for transfusional routines, because a mistake can lead to serious hemolytic reactions. Mechanical measurements performed in agglutinated RBCs can provide valuable information on the type and number of protein bonds. In addition to 


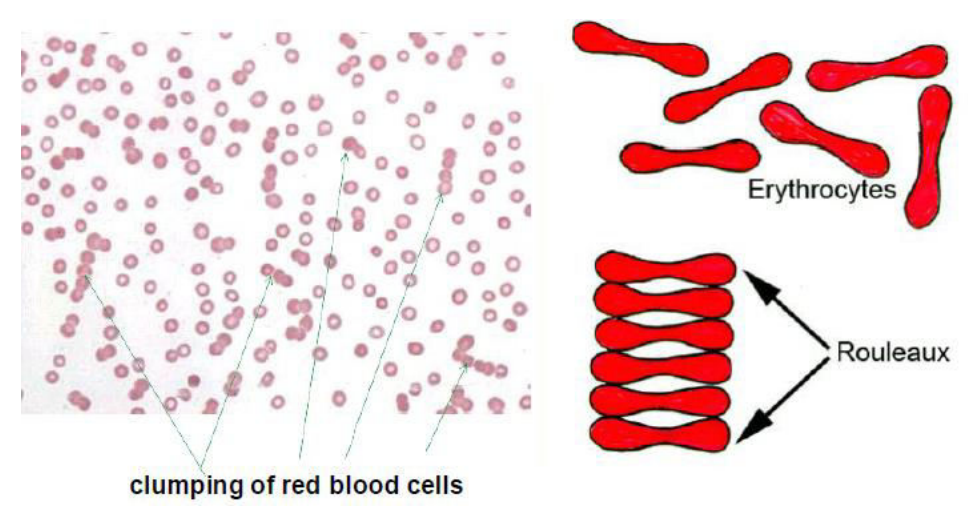

Figure 2. RBCs rouleaux.

protein binding, however, there are a set of barriers to prevent the agglutination process happening spontaneously in the blood stream, which could cause blood clotting. The first barrier is an electric repulsion between different RBCs, which prevents them from coming close to one another.

The fluid lipid bilayer is composed not only by phospholipids but also of glycolipids and cholesterols. Due to the presence of the glycolipids, the RBC membrane surface is negatively charged. This induces a cloud of oppositely charged ions surrounding the cell (the double layer) and creates a repulsive electric (zeta) potential between the cells that prevents them from coming close and, therefore, aggregating in the blood stream [5]. Only the cells that overcome this zeta potential barrier can become sufficiently close together to agglutinate. A common way to enhance the agglutination rate and test sensitivity is to lower the zeta potential. This can be accomplished using low ionic solutions or by the introduction of macromolecular substances, such as dextran, albumin, and PEG (polyethylene glycol), to increase the dielectric constant. Another possibility is to reduce the negative charge of the RBC surface using enzymes such as papain and bromelain [6]. The normal values of erythrocyte sedimentation rate are given in Table 1.

Table 1. Normal value of ESR.

\section{Normal value}

\begin{tabular}{|cccc|}
\hline Age & 20 years & 55 years & 90 years \\
\hline Men & $10 \mathrm{~mm} / \mathrm{hr}$ & $23 \mathrm{~mm} / \mathrm{hr}$ & $45 \mathrm{~mm} / \mathrm{hr}$ \\
\hline Women & $15 \mathrm{~mm} / \mathrm{hr}$ & $30 \mathrm{~mm} / \mathrm{hr}$ & $50 \mathrm{~mm} / \mathrm{hr}$
\end{tabular}




\section{Experimental}

Materials:-

1. ESR solution ( $3.8 \%$ of sodium citrate)

2. Syringe

3. Medical Cotton

4. Ethanol $70 \%$ as antiseptic

5. Westergren pipette

The method [7]:-

1. A venous blood sample was taken from the teaching staff's arm before and after the work.

2. $2 \mathrm{ml}$ blood was taken from each person by a disposable syringe.

3. The blood sample was dropped to heparinized tube.

4. Each tube was labeled with the person identification, name, date of birth and sex of the patient.

5. Add each tube blood sample $0.5 \mathrm{ml}$ of $3.8 \%$ of sodium citrate for ESR.

6. Fill the pipette by sucking blood up to 0 marks and fix it vertically in Westergren stand. Read the upper level of RBC column exactly after $1 \mathrm{hr}$. as shown in Figure 3.

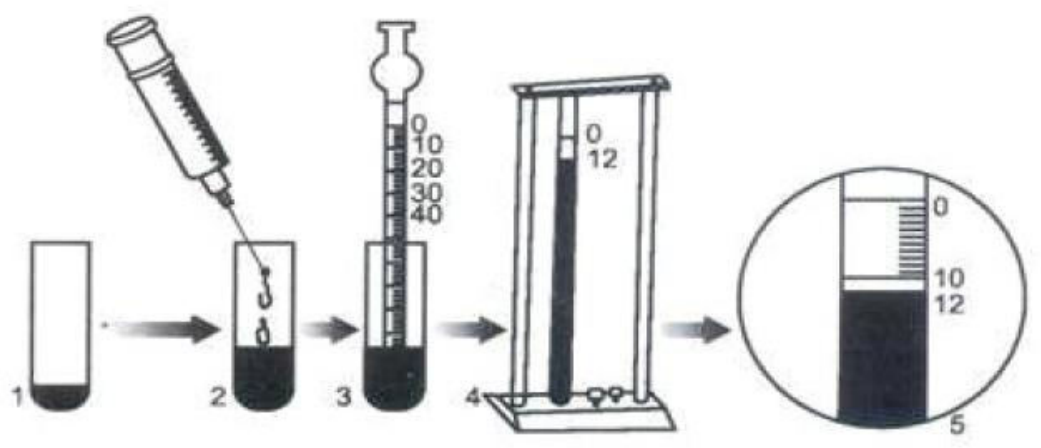



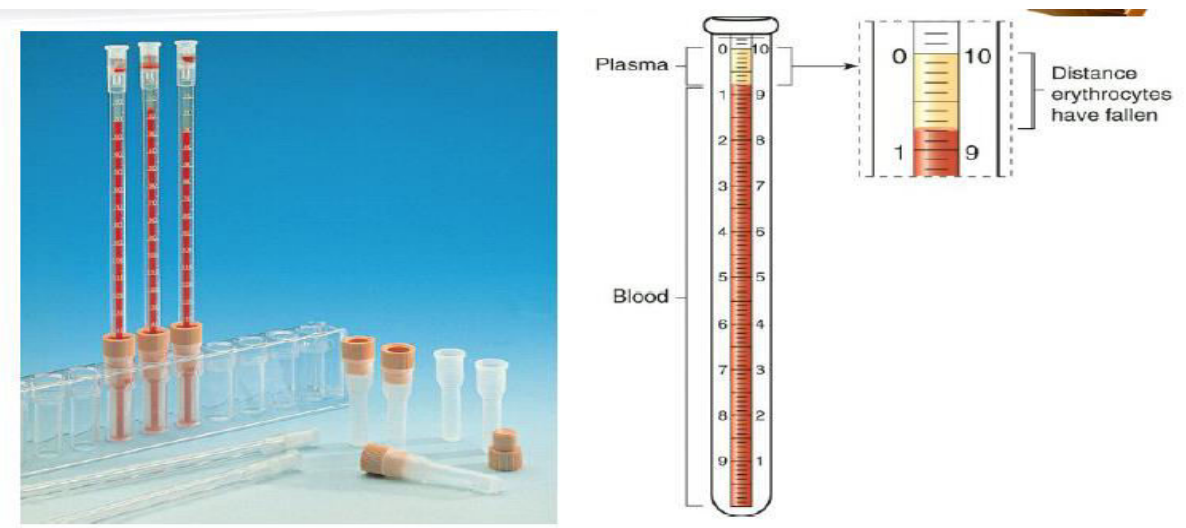

Figure 3. Westergren method.

\section{Result and Discussion}

The mean \pm standard deviation and the probability of ESR before and after working hours are given in Table 2.

Table 2. Statistical analysis of ESR ( $\mathrm{mm}$ in 1st hour)

\begin{tabular}{|l|c|c|c|}
\hline & Number & Mean \pm SD & $p$ \\
\hline The ESR value before working hours & 15 & $9.07 \pm 6.06$ & \multirow{2}{*}{$p<0.05$} \\
\cline { 1 - 3 } The ESR value after working hours & 15 & $11.8 \pm 6.89$ & \\
\hline
\end{tabular}

From this table we note that the probability ratio is smaller than $0.05(p<0.05)$ and this indicates that there is no significant effect.

\section{Conclusion}

This study showed that there is no effect of stress during the working hours on the teaching staffs of Department of Chemistry, Diyala University on the erythrocyte sedimentation rate (ESR). After reviewing the study time table, it was found that the department follows a system that is equivalent to all aspects of the time of lectures and breaks between each lecture, in addition to the explanatory methods used, which led to reduce each the time and stress of the teaching staffs. We recommend that future studies be comprehensive for all departments of college to find the department that different from this results and analysis. 


\section{References}

[1] John A. Koepke, Brian S. Bull, Elkin M. Simson and Onno W. van Assendelft, Reference and Selected Procedure for the Erythrocyte Sedimentation Rate (ESR) Test; Approved Standard-Fourth Edition, USA, 2000.

[2] J. Palmblad, C. G. Karlsson, L. Levi and L. Lidberg, The erythrocyte sedimentation rate and stress, Acta Med. Scand. 205 (1979), 517-520.

[3] B. S. Bull, Clinical and laboratory implications of present ESR methodology, Clin. Lab. Haematol. 3 (1981), 283-298.

[4] Kamakhya Kumar, A study on the impact on stress and anxiety through Yoga nidra, Indian J. Traditional Knowledge 7(3) (2008), 405-409.

[5] F. Van Hunsel, A. Van Gastel, H. Neels, A. Wauters, P. Demedts, K. Bruyland, I. DeMeester, S. Scharpé, A. Janca, C. Song and M. Maes, The influence of psychological stress on total serum protein and patterns obtained in serum protein electrophoresis, Psychol. Med. 28 (1998), 301-309.

[6] Adriana Fontes, Heloise P. Fernandes, André A. de Thomaz, Luiz C. Barbosa, Maria L. Barjas-Castro and Carlos L. Cesar, Measuring electrical and mechanical properties of red blood cells with double optical tweezers, J. Biomed. Opt. 13 (2008), 014001.

[7] S. J. Luner, P. Sturgeon, D. Szklarek and D. T. McQuiston, Effects of proteases and neuraminidase on RBC surface charge and agglutination, Vox Sang. 28 (1975), 184-199.

[8] M. M. Islam, M. R. Amin, M. A. Rahman and D. Akther, Erythrocyte sedimentation rate (ESR) in male adult smokers, Dinajpur Med. Col. J. 6(2) (2013), 180-184. 